\title{
Lower extremities Duplex-Doppler ultrasonography for the detection of suspected deep venous thrombosis: A preliminary report from Sokoto
}

\author{
Shehu B Kakale', Sadisu M Ma`aji², Shamsuddeen A Aliyu ${ }^{3}$ \\ ${ }^{1}$ Consultant Radiologist and Lecturer, ${ }^{2}$ Consultant Radiologist and Associate Professor, ${ }^{3}$ Lecturer, Department of \\ Radiology, Usman Danfodiyo University Teaching Hospital, Sokoto, Nigeria
}

A B S T R A C T

Background: There is a paucity of reports on the deep vein thrombosis in our environment, which creates the impression that the condition is uncommon. Aims and Objectives: The aim of this study is to report the account of our hospital in management of patients with Suspected Lower Extremities Deep Venous Thrombosis using Duplex-Doppler Ultrasonography. Materials and Methods: Between Januarys to December 2014 forty six in patients with suspicion of DVT were evaluated prospectively. All patients presented with symptoms of single or bilateral disease, and a high probability of the disease.Two trained radiologists performed all duplex scan examinations. The patients were scanned using Mindray DC-3/ DC-3T Diagnostic ultrasound scanner (Mindray Bio- Medical Electronics Co., LTD) linear $(7-12 \mathrm{MHz})$ transducers was used. Results: A total of 46 patients had duplex-Doppler scan examination was carried out between January-December 2014. There were 30(65.2\%) males and $16(38.8 \%)$ females subjects recruited for the study. The mean age was $48.9 \pm$ SD 17.3 with range of $18-85$ years. A total of 21 patients $(45.6 \%)$ were found to have deep vein thrombosis (DVTs) on duplex-Doppler examination. Proximal DVTs was seen in $6(12.9 \%)$ and $14(30.3 \%)$ for right and left lower limbs respectively. Distal DVTs was seen in $1(2.2 \%)$ in the right lower limb and 25(54.4\%) show normal findings bilaterally. Diffused DVTs was seen in $2(4.3 \%)$ patients involving external, through popliteal veins on the right lower limb. In $3(6.5 \%)$ of the patients only the common femoral, superficial femoral and popliteal shows diffuse DVTs. Conclusion: With availability of Doppler ultrasound in our environment the diagnosis of DVT is now easier. Duplex scanning techniques are faster, safer, and less expensive. Because of its noninvasive nature, venous duplex is repeatable, allowing for continued follow up after the diagnosis.

Key words: Lower extremities, Duplex-doppler, Ultrasonography
http://nepjol.info/index.php/AJMS DOI: 10.3126/ajms.v7i6.14489 E-ISSN: 2091-0576 P-ISSN: 2467-9100

\section{INTRODUCTION}

Acute or subacute deep vein thrombosis (DVT) usually, but not exclusively, occurs in the legs with an estimated incidence of 1:1000 per year. ${ }^{1}$ Venous thrombosis (VT) is the third most common cardiovascular disease after myocardial infarction and stroke. ${ }^{2}$ Approximately 2 million patients are diagnosed with a deep venous thrombosis annually in the United States with approximately 600,000 hospitalizations and another 200,000 deaths resulting from pulmonary embolism. ${ }^{3-5}$ DVT typically starts distally below the knee but can extend proximally above the knee and potentially result in life-threatening pulmonary embolism. ${ }^{6}$ Pulmonary embolism can occur in 50\%-60\% of patients with untreated DVT, with an associated mortality rate of $25 \%-30 \% .^{5}$ Mortality associated with venous thromboembolism is more commonly seen in patients who present with pulmonary embolism or 
have advanced age, cancer, or underlying cardiovascular disease. $^{7}$

Different approaches to the diagnosis of deep vein thrombosis have been validated in several studies. ${ }^{3-4,8-9}$ There are few reports on DVT in the African literature and have mainly been on postoperative patients. ${ }^{10}$ There is a paucity of reports on the condition in our environment, which creates the impression that the condition is uncommon and in most cases the physician use their clinical assessment to make the diagnosis. However with availability of Doppler ultrasound in our environment the diagnosis of DVT is now easier. Duplex scanningtechniques are faster, safer, and less expensive. Because of its noninvasive nature, venous duplex is repeatable, allowing for continued follow up after the diagnosis. In addition duplex imaging can assess the echogenic characteristic of the thrombus and its degree of adherence to the vein wall. ${ }^{11}$ The clinical presentations of deep vein thrombosis (DVT) in our environment are usually leg pain, swelling and tenderness of the limb. A significant number of these patients have sign and symptoms of venous insufficiency prior presentation which sometime make it difficult to differentiate from recurrent DVT. Deep vein thrombosis is a frequent clinical problemthat can result in substantial mortality due topulmonary embolism. ${ }^{12}$

\section{MATERIALS AND METHODS}

Between Januarys to December 2014 forty six in patients with clinical suspicion of DVT were evaluated prospectively. All patients presented with signs and symptoms of single or bilateral disease, and a high probability of the disease. This study was performed at a single-center, urban, Universityaffiliated teaching Hospital.

Two trained radiologists performed all duplex scan examinations. The patients were scanned using Mindray DC-3/DC-3T Diagnostic ultrasound scanner (Mindray Bio- Medical Electronics Co., LTD) linearmultifrequencial (7-12 MHz) transducers for the limb scan. Venous segments evaluated were external iliac vein, common femoral, superficial femoral, popliteal anterior and posterior tibial veins. Duplex scan examination of the affected limb wasperformed and included gray scale, color Doppler, and spectral evaluation. Directhypoechoic thrombus B-mode identification, and absence of spontaneous or maneuver-induced venous flow were also documented. We excluded patients those with known chronic DVT, patients on anticoagulation prior to ultrasound imaging, patients with plaster of Paris or above-knee amputation, or previously identified acute DVT on comprehensive imaging.There was no distinction made between patients suspected of having a proximal lower extremity deep venous thrombosis or an isolated calf deep venous thrombosis for enrollment purposes. Any patient with a suspected lower extremity deep venous thrombosis was eligible. There were no exclusions made according to sex, ethnicity or weight.

Data collected for this study were maintained in a Microsoft Excel worksheet, with subsequent analysis using SPSS (Version 17.0).

\section{RESULTS}

A total of 46 patients had duplex-Doppler scan examination from the Department of Radiology UsmanuDanfodiyo University Teaching Hospital Sokoto between JanuaryDecember 2014. There were $30(65.2 \%)$ males and $16(38.8 \%)$ females subjects recruited for the study. The mean age was $48.9 \pm$ SD 17.3 with range of $18-85$ years. A total of 21 patients (45.6\%) were found to have deep vein thrombosis(DVTs) on duplex-Doppler examination. Proximal DVTs was seen in 6(12.9\%) and $14(30.3 \%)$ for right and left lower limbs respectively. Distal DVTs was seen in $1(2.2 \%)$ in the right lower limb and 25(54.4\%) show normal findings bilaterally. Diffused DVTs was seen in $2(4.3 \%)$ patients involving external, common femoral, superficial femoral and popliteal veins on the right lower limb. In 3(6.5\%) of the patients only the common femoral, superficial femoral and popliteal shows diffuse DVTs. The most common indication was lower limb swelling and pain accounting for 18(39.2\%), while suspected DVT was 11(23.9\%). Table 1 shows ultrasound findings in all the patients with their frequency and percentages Figure 1. A Bar chart showing age distribution Figure 2a. B-Mode Ultrasound showing a thrombus in femoral vien. Figure $2 \mathrm{~b}$. Duplex-Doppler scan showing absence of Doppler signals in the femoral vein due to thrombus.

\begin{tabular}{lcc}
\multicolumn{3}{l}{ Table 1: Ultrasound findings in all the patients } \\
with their frequency and percentages \\
\hline Diagnosis & Frequency & Percentage \\
\hline Left Normal & 17 & 37.0 \\
Right CFV/SFV/PV DVTs & 2 & 4.3 \\
Right SFV/PV DVTs & 2 & 4.3 \\
Right PV DVTs & 2 & 4.3 \\
Right ATV DVTs & 1 & 2.2 \\
Left EIV/CFV/SFV/PV DVTs & 3 & 6.5 \\
Left PTV DVTs & 1 & 2.2 \\
Left CFV/SFV DVTs & 3 & 6.5 \\
Left CFV/SFV/PV DVTs & 2 & 4.3 \\
Left CFV DVTs & 2 & 4.3 \\
Left SFV & 2 & 4.3 \\
Left PV DVTs & 1 & 2.2 \\
Right Normal & 8 & 17.4 \\
Total & 46 & 100.0 \\
\hline
\end{tabular}




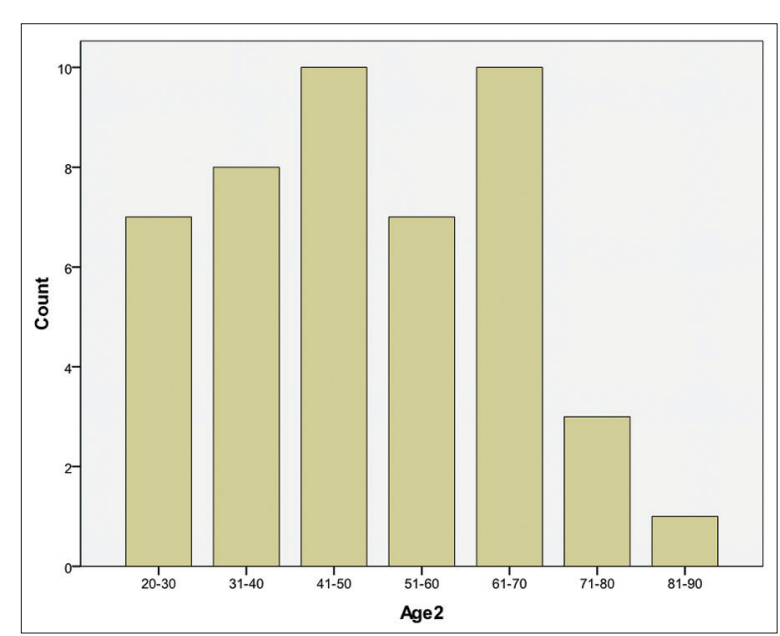

Figure 1: A Bar chart showing age distribution

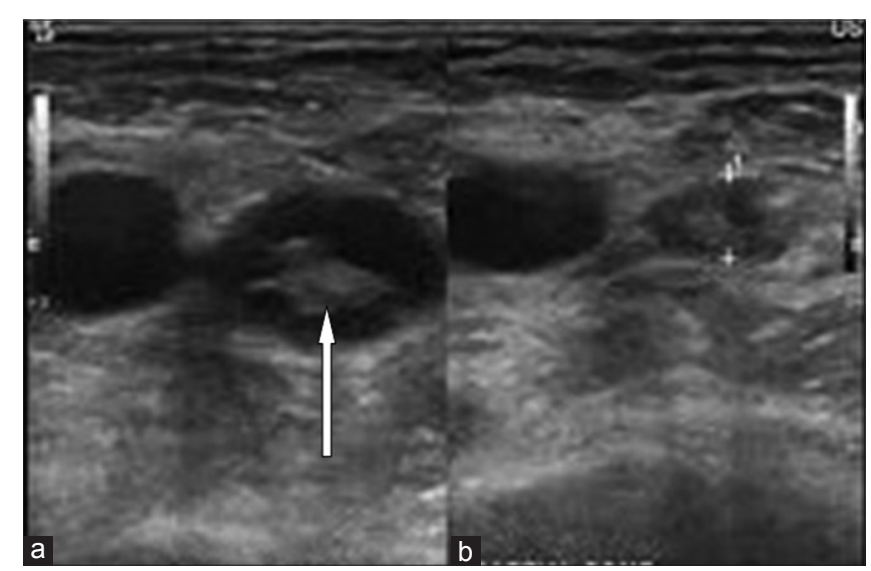

Figure 2: (a) B-Mode Ultrasound showing a thrombus in femoral vien. (b) Duplex-Doppler scan showing absence of Doppler signals in the femoral vein due to thrombus

\section{DISCUSSION}

Deep vein thrombosisis a common but difficult to detect illness that can be fatal if not trated well. Approximately 2 million patients are diagnosed with a deep venous thrombosis annually in the United Stateswith approximately 600,000 hospitalizations and another 200,000 deaths resulting from pulmonary embolism. ${ }^{13-15}$ Venous thrombosis is more common in Europe and USA than in Asia and Africa. Incidence of DVT is reported as $20-35 \%$ in western countries $9.6 \%$ in Sudan and $2.2 \%$ in Malaysia. ${ }^{16-17}$

There is paucity of data in our environment concerning Duplex-Doppler scan diagnosis of DVT.

Previous studies have reported abnormal Duplex-Doppler scan (DUS) findings in only 3.6\% of patients without signs or symptoms suggestive of DVT. ${ }^{18}$ In the present study, only patients with signs or symptoms of DVT in the lower limbs were examined. DVT was confirmed by DUS in $45.6 \%$ of the cases, demonstrating that symptoms and signs suggestive of DVT are very common and can be caused by other clinical conditions. The patient ages from previous studies had already demonstrated that DVT rates increase with age and that $1 / 100$ of individuals $>70$ years old are affected every year. ${ }^{19-21}$ The peaks age groups in our patients was seen between t 40-50 and 61-70 years.

In the past Duplex-Doppler ultrasound and qualified radiologists were not available in our environment as such making diagnosis of DVT was mainly by clinical assessment and venography. Because none of the available imaging modalities have ideal test characteristics, hence the diagnosis of deep venous thrombosis remains challenging. ${ }^{14,22-23}$ Contrast venography exposes the patient to radiation and intravenous contrast material, has special technical requirements that limit its availability, and has associatedmorbidity. ${ }^{1424-26}$ Therefore, duplex ultrasonography with compression ultrasonography, as well as color and flow Doppler ultrasonography of the lower extremity for detecting deep venous thrombosis is recommended because it has sensitivity of $91 \%$ to $96 \%$ and a specificity of $98 \%$ to $100 \% .{ }^{8,26}$ In addition because of its non-invasiveness venous imaging is repeatable. It can also assess the echogenic characteristic of the thrombus at its degree of adherence to the vein wall. ${ }^{11}$ This test also provide important information regarding valves motion and reflux in superficial and deep veins. . $^{27-28}$

Magnetic resonance venography (MRV) is another noninvasive alternative to contrast $\mathrm{x}$-ray venography that shares many of the clinical advantages of Ultrasound, such as not exposing the patient to ionizing radiation or iodinated contrast media. ${ }^{29-32}$ MRV has been shown to successfully diagnose DVT using any variety of pulse sequences or techniques. ${ }^{30-32}$ Despite the wide variety of techniques, however, a recent meta-analysis found MRV to have both high sensitivity (range, $87.5 \%-94.5 \%$; pooled sensitivity, 92\%) and specificity (range, 92.6\%-96.5\%; pooled sensitivity, 95\%). ${ }^{31}$ However because of nonavailability of higher tesla Magnetic resonance imaging machines in our environment in addition to high cost of the examination, MRV was not carried out on our patients.

Computed Tomography Venography (CTV) can also be used to diagnose DVT. ${ }^{31,33-34}$ However, there are the same clinical concerns about its use as there are with contrast $\mathrm{x}$-ray venography, namely, patient exposure to ionizing radiation and iodinated contrast media. In patients who have a suspected pulmonary embolism, a recent metaanalysis found CTV to have high sensitivity (range, 71\%$100 \%$; pooled sensitivity, $95.9 \%$ ) and high specificity (range, $93 \%-100 \%$; pooled specificity, $95.2 \%$ ) comparable to that of Ultrasound for diagnosing proximal DVT. ${ }^{32}$ However CTV may be considered a reasonable alternative to MRV for pelvic DVT or when Ultrasound is non-diagnostic. 
It is clinically important to determine the location and extent of DVT. ${ }^{5,33}$ DVT that is limited to the infrapopliteal calf veins (i.e., below-the-knee or distal DVT) often resolves spontaneously and is rarely associated with pulmonary embolism or other adverse outcomes. ${ }^{5,35-36} \mathrm{Above}$-the-knee or proximal DVT, on the other hand, is strongly associated with the risk of pulmonary embolism. Majority of our patient had above knee DVT. Classically, a patient with symptomatic lower-extremity DVT presents with either local pain or tenderness or with edema and swelling of the lower extremity. However, approximately one-third of patients with DVT do not have any symptoms. ${ }^{1}$ Often, symptoms are not apparent until there is involvement above the knee. ${ }^{5}$ The most common clinical indication in our patients was lower limb swelling and pain accounting for $18(39.2 \%)$.

All the patients in this study did not present with signs and symptoms of pulmonary embolism. However pulmonary embolism can occur in $50 \%-60 \%$ of patients with untreated DVT, with an associated mortality rate of $25 \%-30 \% \%^{5-6}$ Mortality associated with venous thromboembolism is more commonly seen in patients who present with pulmonary embolism or have advanced age, cancer, or underlying cardiovascular disease. ${ }^{7}$ There is always the need to exclude alternative conditions, such as an intact or ruptured Baker's cyst, cellulitis, lymph edema, chronic venous disease, and various musculoskeletal disorders that can clinically mimic DVT during the ultrasound scan. Ultrasound can also be used to tailor the duration of anticoagulant therapy. ${ }^{37}$ The use of Ultrasound in evaluating patients with DVT has limitations especially the level of inguinal and knee regions.

\section{CONCLUSION}

Although ultrasound is highly sensitive and specific for evaluating patients with DVT especially proximally, its sensitive is less for evaluating distal DVT. Majority of our patient had above knee DVT with incidence of about $45.6 \%$. With availability of Doppler ultrasound in our environment the diagnosis of DVT is now easier. Duplex scanning techniques are faster, safer, and less expensive.

\section{ACKNOWLEDGEMENT}

I wish to thank all those that assisted us to write this article.

\section{REFERENCES}

1. Beyer $\mathrm{J}$ and Schellong S. Deep vein thrombosis: Current diagnostic strategy. Eur J Intern Med 2005;16 (4): 238-246.

2. Abildstrom SZ, Rasmussen $S$, Rosen $M$ and Madsen M. Trends in incidence and case fatality rates of acute myocardial infarction in Denmark and Sweden. Heart (British Cardiac Society) 2003;89 (5): 507-511.

3. FitzGerald DE and O'Shaughnessy AM. Compression ultrasonography for diagnosing deep vein thrombosis: One examination of whole leg is better than two of selected parts. BMJ: British Medical Journal 1998;316 (7143): 1532-1532.

4. Bernardi E, Prandoni P, Lensing AW, Agnelli G, Guazzaloca G, Scannapieco G, et al. D-dimer testing as an adjunct to ultrasonography in patients with clinically suspected deep vein thrombosis: prospective cohort study. The Multicentre Italian D-dimer Ultrasound Study Investigators Group. BMJ (Clinical research ed.) 1998;317 (7165): 1037-1040.

5. Kearon C. Natural History of Venous Thromboembolism. Circulation 2003;107 (23 suppl 1): I-22-I-30.

6. Hamper UM, DeJong MR and Scoutt LM. Ultrasound evaluation of the lower extremity veins. Radiol Clin North Am 2007;45 (3): 525-547.

7. White RH. The Epidemiology of Venous Thromboembolism. Circulation 2003;107 (23 suppl 1): I-4-I-8.

8. Wells PS, Anderson DR, Bormanis J, Guy F, Mitchell M, Gray L, et al. Value of assessment of pretest probability of deep-vein thrombosis in clinical management. Lancet 1997;350 (9094): 1795-1798.

9. Perrier A, Desmarais S, Miron MJ, de Moerloose P, Lepage R, Slosman D, et al. Non-invasive diagnosis of venous thromboembolism in outpatients. Lancet 1999;353 (9148): 190-195

10. Aduful HK and Darko R. Deep Venous Thrombosis of the Lower Limb in Young Ambulant Ghanaians. Ghana Medical Journal 2007;41 (1): 17-20.

11. Khilnani NM and Min RJ. Imaging of Venous Insufficiency. Seminars in Interventional Radiology 2005;22 (3): 178-184.

12. Lensing AW, Prandoni $P$, Prins $M H$ and Buller HR. Deep-vein thrombosis. Lancet 1999;353 (9151): 479-485.

13. Silverstein MD, Heit JA, Mohr DN, Petterson TM, O'Fallon W, Melton $\mathrm{L}$, et al. Trends in the incidence of deep vein thrombosis and pulmonary embolism: A 25-year population-based study. Archives of Internal Medicine 1998;158 (6): 585-593.

14. Hirsh $\mathrm{J}$ and Hoak J. Management of deep vein thrombosis and pulmonary embolism. A statement for healthcare professionals. Council on Thrombosis (in consultation with the Council on Cardiovascular Radiology), American Heart Association. Circulation 1996;93 (12): 2212-2245.

15. Weinmann EE and Salzman EW. Deep-Vein Thrombosis. New England Journal of Medicine 1994;331 (24): 1630-1641.

16. Cerrato $D$, Ariano $C$ and Fiacchino F. Deep vein thrombosis and low-dose heparin prophylaxis in neurosurgical patients. Journal of neurosurgery 1978;49 (3): 378-381.

17. Hassan MA, Rahman EA and Rahman IA. Prostatectomy and deep vein thrombosis in Sudanese patients. The British journal of surgery 1974;61 (8): 650-652.

18. Marik PE, Andrews $L$ and Maini $B$. The Incidence of Deep Venous Thrombosis in ICU Patients. Chest 1997;111 (3): 661-664.

19. Fowkes FJ, Price JF and Fowkes FG. Incidence of diagnosed deep vein thrombosis in the general population: systematic review. European journal of vascular and endovascular surgery: the official journal of the European Society for Vascular Surgery 2003;25 (1): 1-5.

20. Useche JN, de Castro AM, Galvis GE, Mantilla RA and Ariza A. Use of US in the evaluation of patients with symptoms of deep venous thrombosis of the lower extremities. Radiographics: a review publication of the Radiological Society of North America, Inc 2008;28 (6): 1785-1797. 
21. de Oliveira A, França GJ, Vidal EA, Stalke PSDB and Baroncini LAV. Duplex scan in patients with clinical suspicion of deep venous thrombosis. Cardiovascular Ultrasound 2008;6: 53-53.

22. Wells PS, Hirsh J, Anderson DR, Lensing AW, Foster G, Kearon C, et al. Accuracy of clinical assessment of deep-vein thrombosis. Lancet 1995;345 (8961): 1326-1330.

23. Lensing AW, Prandoni P, Brandjes D, Huisman PM, Vigo M, Tomasella G, et al. Detection of deep-vein thrombosis by realtime B-mode ultrasonography. The New England journal of medicine 1989;320 (6): 342-345.

24. Gaitini D. Current approaches and controversial issues in the diagnosis of deep vein thrombosis via duplex Doppler ultrasound. Journal of clinical ultrasound: JCU 2006;34 (6):289-297.

25. Tomkowski WZ, Davidson BL, Wisniewska J, Malek G, Kober J, Kuca $P$, et al. Accuracy of compression ultrasound in screening for deep venous thrombosis in acutely ill medical patients. Thrombosis and haemostasis 2007;97 (2): 191-194.

26. van Ramshorst $B$, Legemate DA, Verzijlbergen JF, Hoeneveld $\mathrm{H}$, Eikelboom BC, de Valois JC, et al. Duplex scanning in the diagnosis of acute deep vein thrombosis of the lower extremity. European journal of vascular surgery 1991;5 (3): 255-260.

27. Rollins DL, Semrow CM, Friedell ML and Buchbinder D. Use of ultrasonic venography in the evaluation of venous valve function. American journal of surgery 1987;154 (2): 189-191

28. Welch HJ, Young CM, Semegran AB, lafrati MD, Mackey WC and O'Donnell TF. Duplex assessment of venous reflux and chronic venous insufficiency: the significance of deep venous reflux. Journal of vascular surgery 1996;24 (5): 755-762.

29. Carpenter JP, Holland GA, Baum RA, Owen RS, Carpenter JT and Cope $\mathrm{C}$. Magnetic resonance venography for the detection of deep venous thrombosis: comparison with contrast venography and duplex Doppler ultrasonography. Journal of vascular surgery 1993;18 (5): 734-741.

30. Evans, AJ, Sostman HD, Witty LA, Paulson EK, Spritzer CE,
Hertzberg B, et al. Detection of deep venous thrombosis: prospective comparison of MR imaging and sonography. Journal of magnetic resonance imaging: JMRI 1996;6 (1): 44-51.

31. Sampson FC, Goodacre SW, Thomas SM and van Beek EJ. The accuracy of MRI in diagnosis of suspected deep vein thrombosis: systematic review and meta-analysis. Eur Radiol 2007;17 (1); 175-181.

32. Thomas SM, Goodacre SW, Sampson FC and van Beek EJ. Diagnostic value of CT for deep vein thrombosis: results of a systematic review and meta-analysis. Clin Radiol 2008;63 (3): 299-304.

33. Goodacre S, Sampson F, Stevenson M, Wailoo A, Sutton A, Thomas $S$, et al. Measurement of the clinical and costeffectiveness of non-invasive diagnostic testing strategies for deep vein thrombosis. Health technology assessment (Winchester, England) 2006;10 (15): 1-168.

34. Loud PA, Katz DS, Klippenstein DL, Shah RD and Grossman ZD. Combined CT venography and pulmonary angiography in suspected thromboembolic disease: diagnostic accuracy for deep venous evaluation. AJR Am J Roentgenol 2000;174 (1): 61-65.

35. Gottlieb RH, Voci SL, Syed L, Shyu C, Fultz PJ, Rubens DJ, et al. Randomized prospective study comparing routine versus selective use of sonography of the complete calf in patients with suspected deep venous thrombosis. AJR Am J Roentgenol 2003;180 (1): 241-245.

36. Righini M, Le Gal G, Aujesky D, Roy PM, Sanchez O, Verschuren $\mathrm{F}$, et al. Complete venous ultrasound in outpatients with suspected pulmonary embolism. Journal of thrombosis and haemostasis: JTH 2009;7 (3): 406-412.

37. Prandoni $P$, Prins $M H$, Lensing AWA, Ghirarduzzi A, Ageno W, Imberti D, et al. Residual Thrombosis on Ultrasonography to Guide the Duration of Anticoagulation in Patients With Deep Venous ThrombosisA Randomized Trial. Annals of internal medicine 2009;150 (9): 577-585.

Authors Contribution:

SMM - Concept and design of the study, reviewed the literature, manuscript preparation and critical revision of the manuscript; SBK - Concept, collected data and review of literature and helped in preparing first draft of manuscript; SAA - Conceptualized study, literature search, statistically analyzed and interpreted, prepared first draft of manuscript and critical revision of the manuscript.

Source of Support: Nil, Conflict of Interest: None declared. 